\title{
Daily duration of long-term oxygen therapy and risk of hospitalization in oxygen-dependent COPD patients
}

This article was published in the following Dove Press journal: International Journal of COPD

Josefin Sundh'

Zainab Ahmadi ${ }^{2}$

Magnus Ekström²

'Department of Respiratory Medicine, School of Medical Sciences, Örebro University, Örebro, Sweden; ${ }^{2}$ Department of Clinical Sciences, Division of Respiratory Medicine and Allergology, Lund University, Lund, Sweden
Correspondence: Josefin Sundh Department of Respiratory Medicine, School of Medical Sciences, Örebro University, Örebro 70182, Sweden $\mathrm{Tel}+46702349517$

Fax +46 I9 186526

Email josefin.sundh@oru.se
Introduction: Long-term oxygen therapy (LTOT) improves survival and may reduce hospital admissions in patients with chronic obstructive pulmonary disease (COPD) and severe hypoxemia, but the impact of daily duration of LTOT on hospitalization rate is unknown. We aimed to estimate the association between the daily duration of LTOT (24 vs $15 \mathrm{~h} / \mathrm{d}$ ) and hospital admissions in patients with LTOT due to COPD.

Materials and methods: A population-based, cohort study included patients who started LTOT due to COPD between October 1, 2005 and June 30, 2009 in the Swedish national register for respiratory failure (Swedevox). Time to first hospitalization from all causes and from respiratory or nonrespiratory disease, using the National Patient Registry, was analyzed using Fine-Gray regression, adjusting for potential confounders.

Results: A total of 2,249 patients with COPD (59\% women) were included. LTOT $24 \mathrm{~h} / \mathrm{d}$ was prescribed to 539 (24\%) and LTOT 15-16 h/d to 1,231 (55\%) patients. During a median follow-up of 1.1 years (interquartile range, 0.6-2.1 years), 1,702 (76\%) patients were hospitalized. No patient was lost to follow-up. The adjusted rate of all-cause hospitalization was similar between LTOT 24 and 15-16 h/d (subdistribution hazard ratio [SHR] 0.96; [95\% CI] 0.84-1.08), as was cause-specific hospitalizations analyzed for respiratory disease (SHR: $1.00 ; 95 \% \mathrm{CI}$ : 0.86-1.17) and nonrespiratory disease (SHR: 0.92; 95\% CI: 0.75-1.14).

Conclusion: LTOT prescribed for $24 \mathrm{~h} / \mathrm{d}$ was not associated with decreased hospitalization rates compared with LTOT for $15-16 \mathrm{~h} / \mathrm{d}$ in patients with oxygen-dependent COPD. The results should be validated in a randomized controlled trial.

Keywords: long-term oxygen therapy, chronic obstructive pulmonary disease, duration, hospitalization, cohort study, hypoxemia, hospital admission, respiratory disease, nonrespiratory disease

\section{Introduction}

Chronic obstructive pulmonary disease (COPD) is the most common cause of hypoxic respiratory failure. Long-term oxygen therapy (LTOT) improves survival in patients with chronic severe hypoxemia due to COPD. ${ }^{1,2}$ The current recommendation to use LTOT at least $15 \mathrm{~h} / \mathrm{d}$ but preferably $24 \mathrm{~h} / \mathrm{d}$ is based on the Medical Research Council (MRC) and the Nocturnal Oxygen Therapy Trial (NOTT) studies performed in the 1970s. ${ }^{1,2}$ In the MRC trial, LTOT $15 \mathrm{~h} / \mathrm{d}$ was compared with no oxygen, and in the NOTT, LTOT 24 h/d was compared with nocturnal LTOT 12 h/d. ${ }^{1,2}$ In an observational comparison of the treatment arms of these 2 trials, the crude mortality rate was lower for the $18 \mathrm{~h} / \mathrm{d}$ group in NOTT than for the $15 \mathrm{~h} / \mathrm{d}$ group in the MRC trial. ${ }^{1,2,3}$ The comparison was unadjusted and involved only 290 patients. ${ }^{1,2,3}$ A recent observational 
study of 2,249 patients with oxygen-dependent COPD found no survival benefit from LTOT 24 vs $15 \mathrm{~h} / \mathrm{d}^{4}$

Patients with oxygen-dependent COPD form a vulnerable group with impaired exercise tolerance and health-related quality of life,${ }^{5}$ high risk of anxiety and depression, and high risk of hospitalizations associated with suffering and high health care costs. ${ }^{6}$ Thus, it is critical to explore factors influencing these measurements. LTOT has been reported to be associated with reduced hospital admissions in patients with COPD and hypoxic respiratory failure. ${ }^{7}$ However, LTOT in moderate hypoxemia ${ }^{8}$ intermittent oxygen use at home, ${ }^{9}$ or oxygen treatment at exercise ${ }^{10}$ do not prevent hospital admissions. The impact of LTOT duration on hospital admissions is unknown. This issue is of clinical importance as higher duration or continuous LTOT may pose an unnecessary burden and limitation for many patients. Dependence on LTOT has been shown to be associated with increased feelings of anxiety, and shame, potentially leading to social isolation and restrictions in activities in daily life. ${ }^{11,12}$

The aim of the present study was to estimate the association between LTOT daily duration and hospital admissions in patients with COPD and hypoxic respiratory failure. We hypothesized that hospitalizations would not differ in people prescribed LTOT 24 h/d compared with LTOT 15 h/d.

\section{Materials and methods}

\section{Study design and data collection}

This was a population-based, retrospective cohort study of prospectively collected data from the Swedish national register for respiratory failure (Swedevox). The structure, validity, and coverage of Swedevox have been described elsewhere. ${ }^{13}$ All 48 Swedish centers prescribing LTOT follow the national guidelines that LTOT should be prescribed for $15 \mathrm{~h} / \mathrm{d}$ or more, and that LTOT is indicated when arterial blood gas tension of oxygen $\left(\mathrm{PaO}_{2}\right)$ breathing ambient air is $<7.4 \mathrm{kPa}$; or $\mathrm{PaO}_{2} 7.4-8.0 \mathrm{kPa}$ together with signs of rightsided heart failure/pulmonary hypertension and/or secondary polycythemia erythrocyte volume fraction $>0.54 .{ }^{13}$

The present study included all registered patients who started LTOT due to COPD and hypoxic respiratory failure between October 1, 2005 and June 30, 2009. Patients with COPD and comorbid diagnosis of lung cancer before starting LTOT were excluded. For patients who started LTOT more than once during the period, only the most recent treatment was included in the analysis.

\section{Patient characteristics and measures}

Variables were registered prospectively in Swedevox at the start of LTOT including on resting arterial $\mathrm{PaO}_{2}$ and blood gas tension of carbon dioxide $\left(\mathrm{PaCO}_{2}\right)$ breathing air and oxygen, forced expiratory volume in 1 second $\left(\mathrm{FEV}_{1}\right)$, body mass index (BMI), World Health Organization (WHO) performance status, prescribed oxygen dose (L/min), and prescribed LTOT duration $(\mathrm{h} / \mathrm{d})$. Data on comorbid conditions and number of hospitalizations during the 4-year period before baseline were obtained from the Swedish National Inpatient Register, which covers more than $99 \%$ of all hospital admissions and about $80 \%$ of all hospital-based outpatient care during period. ${ }^{14}$ Comorbid conditions were defined as doctor's diagnoses coded according to the tenth revision of the International Classification of Disease. Diagnoses of interest were anxiety, renal failure, and cardiovascular disease. The latter was expressed as number of cardiovascular diseases (cerebrovascular disease, heart failure, hypertension, ischemic heart disease, peripheral artery disease, pulmonary embolism, or other circulatory disease). Data on all dispensed drug prescriptions in outpatient care after July 1, 2005 were obtained from the Swedish Prescribed Drug Register. ${ }^{15}$ Vital status and cause of death were obtained from the National Board of Health and Welfare's Cause of Death Register. ${ }^{16}$

\section{Ethical considerations}

All patients participating in the study were informed according to directives from the authorities. Participants provided their verbal consent when registering in Swedevox, and the consent procedure and the study was approved by the Regional Ethical Review Board of Lund (DNr 157/2007 and 350/2008), the Swedish National Board of Health and Welfare, and the Swedish Data Inspection Board.

\section{Statistical analyses}

Statistical analyses were conducted using the software packages Stata, version 13 (StataCorp LP; College Station, TX, USA), and SAS, version 9.3 (SAS Institute, Inc., Cary, NC, USA).

Continuous baseline variables were presented as means with standard deviations (SD) or medians with range or interquartile range (IQR) for normal and skewed distribution, respectively. Categorical variables were expressed as frequencies and percentages.

The follow-up period was from start of LTOT until first hospital admission, with censoring due to death, LTOT withdrawal, or study end at the 30th of June, 2009. The primary endpoint was time to first hospitalization, and secondary endpoints were time to first hospitalization due to respiratory disease (tenth revision of the International Classification of Disease, J00-J99) or nonrespiratory disease including cardiovascular diseases and other diseases. Analyses were 
conducted using Fine-Gray regression, accounting for the competing risk of death. Prescribed LTOT daily duration was analyzed both by comparing $24 \mathrm{~h} / \mathrm{d}$ with $15 \mathrm{~h} / \mathrm{d}$ $(n=1,770$ patients) and as a continuous variable $(n=2,249)$, with adjustment for potential confounders. The confounders were chosen a priori using subject matter knowledge and prior mortality analyses ${ }^{17-19}$ and included baseline age, sex, prescribed oxygen dose (L/min), $\mathrm{PaO}_{2}$ (on air), $\mathrm{PaCO}_{2}$ (on air), $\mathrm{FEV}_{1}$, WHO performance status (in 5 categories), BMI (in 4 categories), maintenance treatment with oral glucocorticoids, anxiety, renal failure, number of cardiovascular diagnoses (3 categories), and number of hospitalizations in 4 years before baseline (continuous variable). Missing data were imputed for $\mathrm{PaO}_{2}$ (air), $\mathrm{PaCO}_{2}$ (air), $\mathrm{FEV}_{1}$, BMI, and WHO performance status. ${ }^{17}$ The model estimates were robust to the imputations. Statistical significance was defined as 2 -sided $P$-value $<0.05$.

\section{Results}

\section{Patient characteristics}

During October 1, 2005-December 31, 2009; a total of 2,249 patients with COPD (59\% women) started LTOT and were included in the analysis. Due to the comprehensive coverage of the Swedish National Inpatient Register, follow-up was complete. LTOT $24 \mathrm{~h} / \mathrm{d}$ was prescribed to 539 (24\%) patients, LTOT $15-16 \mathrm{~h} / \mathrm{d}$ was prescribed to 1,231 (55\%) patients, and other daily durations were prescribed to 470 patients $(21 \%)$. Patients receiving LTOT $24 \mathrm{~h} / \mathrm{d}$ had significantly lower $\mathrm{PaO}_{2}$ on air and worse WHO performance status at the start of LTOT, as compared with patients with oxygen $15 \mathrm{~h} / \mathrm{d}$ (Table 1). The aimed $\mathrm{PaO}_{2}$ at above $8 \mathrm{kPa}$ on oxygen was achieved in the majority of patients, with similar rates for LTOT $24 \mathrm{~h} / \mathrm{d}(77 \%)$ and LTOT 15-16 h/d (80\%).

\section{Hospital admissions}

Median follow-up time was 1.1 years (IQR, 0.6-2.1 years), and 1,702 (76\%) patients were hospitalized at least 1 time during the follow-up period. Of these, 8 patients were hospitalized during the whole study period and excluded from regression analysis. The remaining patients were censored due to death before any hospital admission $(n=190 ; 8 \%)$ or due to withdrawal from LTOT $(n=357 ; 16 \%)$. In the majority of the patients, their first hospitalization was due to worsening of respiratory disease $(n=1,105)$. In 16 of the included

Table I Baseline characteristics

\begin{tabular}{|c|c|c|c|c|}
\hline \multirow[t]{2}{*}{ Characteristics } & \multirow{2}{*}{$\begin{array}{l}\text { All patients with } \\
\text { LTOT, } N=2,249\end{array}$} & \multicolumn{3}{|c|}{ Patients with prescribed LTOT duration $24 \mathrm{~h} / \mathrm{d}$ or $15 \mathrm{~h} / \mathrm{d}$} \\
\hline & & $\begin{array}{l}\text { LTOT } 24 \text { h/d } \\
\text { N=539 (24\%) }\end{array}$ & $\begin{array}{l}\text { LTOT I } 5 \text { h/d } \\
\mathbf{N}=\text { I,23 I (55\%) }\end{array}$ & $P$-values \\
\hline Age, years (SD) & $74.7 \pm 8.2$ & $75.0 \pm 8.1$ & $74.7 \pm 8.2$ & 0.57 \\
\hline Women, n (\%) & I,328 (59) & $283(53)$ & $767(62)$ & $<0.001$ \\
\hline $\mathrm{PaO}_{2}$ air, $\mathrm{kPa}$ & $6.5 \pm 0.9$ & $6.3 \pm 0.9$ & $6.6 \pm 0.8$ & $<0.001$ \\
\hline $\mathrm{PaO}_{2}$ oxygen, $\mathrm{kPa}^{\mathrm{a}}$ & $8.7 \pm 1.1$ & $8.6 \pm 1.1$ & $8.7 \pm 1.1$ & 0.006 \\
\hline $\mathrm{PaCO}_{2}$ air, $\mathrm{kPa}$ & $6.3 \pm 1.2$ & $6.2 \pm 1.3$ & $6.2 \pm 1.2$ & 0.90 \\
\hline $\mathrm{PaCO}_{2}$ oxygen, $\mathrm{kPa}^{\mathrm{b}}$ & $6.5 \pm 1.3$ & $6.6 \pm 1.3$ & $6.5 \pm 1.3$ & 0.12 \\
\hline $\mathrm{FEV}_{1}, \mathrm{~L}^{\mathrm{c}}$ & $0.84 \pm 0.48$ & $0.89 \pm 0.54$ & $0.83 \pm 0.45$ & 0.10 \\
\hline $\mathrm{FEV}_{1}, \%$ pred & $33.6 \pm 17.3$ & $34.8 \pm 19.5$ & $33.8 \pm 17.0$ & 0.45 \\
\hline Prescribed oxygen dose, L/min & $1.6 \pm 1.3$ & $2.0 \pm \mathrm{I} .3$ & $1.5 \pm 1.0$ & $<0.001$ \\
\hline Ever smoking, n (\%) & $2,106(94)$ & $478(89)$ & $\mathrm{I}, \mathrm{I} I 0(90)$ & 0.35 \\
\hline $\mathrm{BMI}, \mathrm{kg} / \mathrm{m}^{2 \mathrm{~d}}$ & $24.0(6.3)$ & $24.0(6.4)$ & $23.9(6.0)$ & 0.80 \\
\hline \multicolumn{5}{|l|}{ WHO performance status, $n(\%)^{e}$} \\
\hline 0 & $132(6)$ & $26(5)$ & $76(6)$ & 0.26 \\
\hline I & 881 (39) & $173(32)$ & $493(40)$ & 0.001 \\
\hline 2 & $7 \mid 4(32)$ & $167(31)$ & $385(31)$ & 0.90 \\
\hline 3 & 292 (I3) & $108(20)$ & $132(11)$ & $<0.001$ \\
\hline 4 & $31(1)$ & II (2) & $14(1)$ & 0.14 \\
\hline \multicolumn{5}{|l|}{ Cardiovascular diagnoses, n (\%) } \\
\hline 0 & $755(34)$ & $158(29)$ & $428(35)$ & 0.03 \\
\hline I & $823(37)$ & $203(38)$ & $433(35)$ & 0.32 \\
\hline 2 & $449(20)$ & $1 \mid 3(2 \mid)$ & $242(20)$ & 0.53 \\
\hline$\geq 3$ & $222(10)$ & $65(12)$ & $128(10)$ & 0.30 \\
\hline Anxiety, n (\%) & $196(9)$ & $44(8)$ & $123(10)$ & 0.23 \\
\hline Renal failure, n (\%) & $97(4)$ & $28(5)$ & $57(5)$ & 0.60 \\
\hline Oral glucocorticoids, n (\%) & $\mathrm{I}, 375(6)$ & $327(6 \mathrm{I})$ & $731(60)$ & 0.61 \\
\hline
\end{tabular}

Notes: Data presented as mean \pm SD unless otherwise specified. Hospitalizations and diagnoses were assessed within the 4-year period before the start of LTOT. a Missing data $n=289$. ' Missing data $n=301$. ' Missing data $n=849$. ${ }^{d}$ Missing data $n=701$. e Missing data $n=199$.

Abbreviations: $\mathrm{BMI}$, body mass index; $\mathrm{FEV}_{1}$, forced expiratory volume in I second; LTOT, long-term oxygen therapy; $\mathrm{PaCO}_{2}$, arterial blood gas tension of carbon dioxide; $\mathrm{PaO}_{2}$, arterial blood gas tension of oxygen; SD, standard deviations; WHO, World Health Organization. 
hospitalization events, a main diagnosis code was missing, and these patients were excluded from cause-specific regression analysis.

\section{Hospital admissions in LTOT 24 vs I5- $16 \mathrm{~h} / \mathrm{d}$}

In the crude analysis, comparing LTOT $24 \mathrm{~h} / \mathrm{d}$ and $15-16 \mathrm{~h} / \mathrm{d}$ $(n=1,763)$, there was no difference in all-cause hospitalizations (subdistribution hazard ratio [SHR]: 0.96; 95\% CI: 0.86-1.08). In the multivariate model with adjustment for potential confounders, the result remained almost exactly the same (SHR: 0.96; 95\% CI: 0.84-1.08) (Table 2). The adjusted cumulative function plots of the treatment groups closely overlapped at all time points (Figure 1). When the continuous LTOT duration variable was used $(n=2,249)$, the SHR was similar (SHR: 0.99; 95\% CI: 0.98-1.01). Adjusted cause-specific hospitalizations due to respiratory disease was similar between the 2 treatment groups (SHR: 1.00;

Table 2 Results from Fine-Gray regression of LTOT duration and hospitalizations

\begin{tabular}{|c|c|c|}
\hline Characteristics & SHR (95\% CI) & P-values \\
\hline Oxygen duration $24 \mathrm{~h} / \mathrm{d}$ & $0.96(0.84-1.08)$ & 0.48 \\
\hline Age, per I year & $1.00(0.99-1.00)$ & 0.19 \\
\hline Women & $1.05(0.92-1.19)$ & 0.46 \\
\hline $\mathrm{PaO}_{2}$ air, per I kPa & $0.99(0.93-1.06)$ & 0.80 \\
\hline $\mathrm{PaCO}_{2}$ air, per I kPa & $0.66(0.48-0.90)$ & 0.01 \\
\hline $\mathrm{FEV}_{1}$, per I L & $0.91(0.76-1.08)$ & 0.28 \\
\hline Prescribed oxygen dose, per I L/min & $0.99(0.94-1.05)$ & 0.82 \\
\hline \multicolumn{3}{|l|}{$\mathrm{BMI}, \mathrm{kg} / \mathrm{m}^{2}$} \\
\hline$<18.5$ & $1.02(0.86-\mid .21)$ & 0.85 \\
\hline $18.5-24.9$ & Ref & \\
\hline $25.0-29.9$ & $0.95(0.82-I . I I)$ & 0.51 \\
\hline$\geq 30.0$ & $1.02(0.84-1.23)$ & 0.86 \\
\hline \multicolumn{3}{|l|}{ WHO performance status } \\
\hline 0 & Ref & \\
\hline 1 & $\mathrm{I} .07(0.85-\mathrm{I} .34)$ & 0.58 \\
\hline 2 & I.II (0.88-I.4I) & 0.38 \\
\hline 3 & $0.97(0.73-1.29)$ & 0.83 \\
\hline 4 & $0.52(0.26-1.05)$ & 0.07 \\
\hline \multicolumn{3}{|l|}{ Cardiovascular diagnoses } \\
\hline 0 & Ref & \\
\hline I & I.I $3(0.99-1.28)$ & 0.07 \\
\hline 2 & I.3I (I.II-I.54) & 0.001 \\
\hline$\geq 3$ & $1.42(1.16-1.75)$ & 0.001 \\
\hline Anxiety & I.I8 (0.97-I.43) & 0.09 \\
\hline Renal failure & I.22 (0.94-I.58) & 0.13 \\
\hline Oral glucocorticoids & $1.39(1.24-1.55)$ & $<0.0001$ \\
\hline
\end{tabular}

Notes: Data from Fine-Gray analyses adjusted for baseline age, sex, oxygen dose (L/min), $\mathrm{PaO}_{2}$ (air), baseline $\mathrm{PaCO}_{2}$ (air), $\mathrm{FEV}$, WHO performance status, BMI, treatment with oral glucocorticoids, and comorbid conditions including anxiety, renal failure, and number of cardiovascular diagnoses. An SHR above I indicates an increased risk for hospitalization.

Abbreviations: BMI, body mass index; $\mathrm{FEV}_{1}$, forced expiratory volume in I second; LTOT, long-term oxygen therapy; $\mathrm{PaCO}_{2}$, arterial blood gas tension of carbon dioxide; $\mathrm{PaO}_{2}$, arterial blood gas tension of oxygen; Ref, reference; SHR, subdistribution hazard ratio; WHO, World Health Organization.

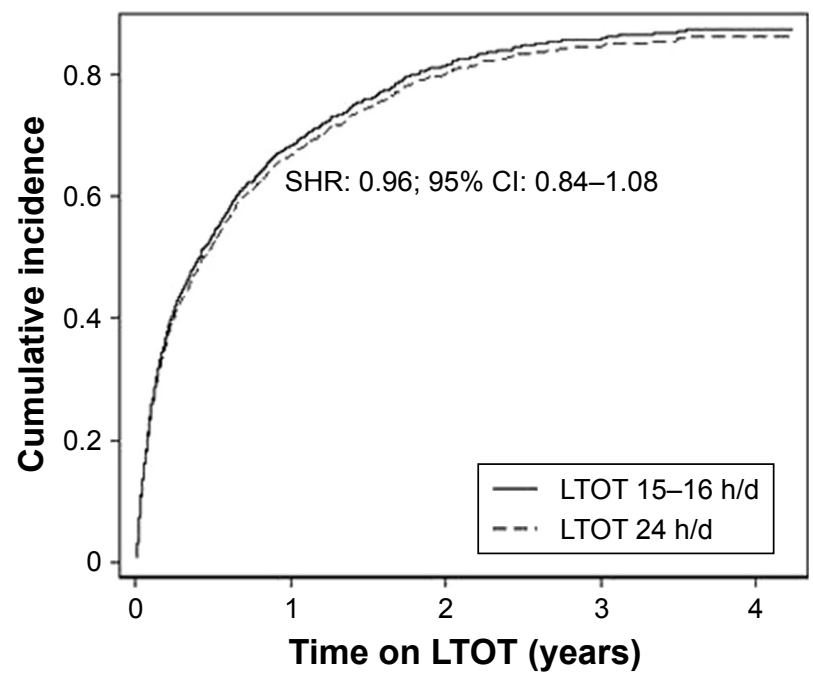

Figure I Cumulative incidence of first hospitalization in LTOT daily duration $24 \mathrm{~h} / \mathrm{d}$ vs $15 \mathrm{~h} / \mathrm{d}$.

Note: Results from Fine-Gray analyses adjusted for baseline age, sex, oxygen dose (L/min), $\mathrm{PaO}_{2}$ (air), baseline $\mathrm{PaCO}_{2}$ (air), $\mathrm{FEV}, \mathrm{WHO}$ performance status, body mass index, treatment with oral glucocorticoids, and comorbid conditions including anxiety, renal failure and number of cardiovascular diagnoses.

Abbreviations: $\mathrm{FEV}_{1}$, forced expiratory volume in one second; LTOT, long-term oxygen therapy; $\mathrm{PaCO}_{2}$, arterial blood gas tension of carbon dioxide; $\mathrm{PaO}_{2}$, arterial blood gas tension of oxygen; SHR, subdistribution hazard ratio; WHO, World Health Organization.

95\% CI: 0.86-1.17), as was the rate of hospitalizations due to nonrespiratory cause (SHR: $0.92 ; 95 \% \mathrm{CI}: 0.75-1.14$ ) (Figure 2).

\section{Discussion \\ Main findings}

The primary finding of this study is that the rate of hospitalization due to any cause or due to respiratory disease is equal

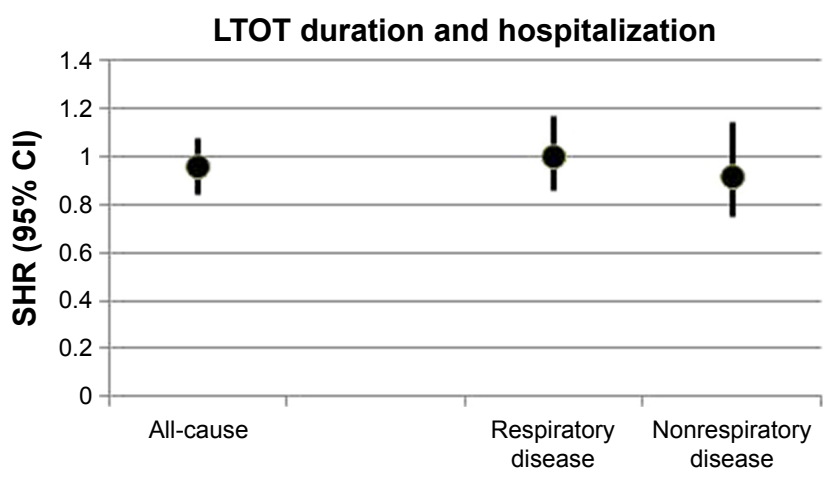

Figure 2 All-cause and cause-specific hospitalizations in LTOT daily duration $24 \mathrm{~h} / \mathrm{d}$ vs $15 \mathrm{~h} / \mathrm{d}$.

Note: Results from Fine-Gray analyses of LTOT 24 h/d vs 15 h/d adjusted for baseline age, sex, oxygen dose (L/min), $\mathrm{PaO}_{2}$ (air), baseline $\mathrm{PaCO}_{2}$ (air), $\mathrm{FEV}, \mathrm{WHO}$ performance status, body mass index, treatment with oral glucocorticoids, and comorbid conditions including anxiety, renal failure and number of cardiovascular diagnoses.

Abbreviations: $\mathrm{FEV}_{1}$, forced expiratory volume in one second; LTOT, long-term oxygen therapy; $\mathrm{PaCO}_{2}$, arterial blood gas tension of carbon dioxide; $\mathrm{PaO}_{2}$, arterial blood gas tension of oxygen; SHR, subdistribution hazard ratio; WHO, World Health Organization. 
with LTOT $24 \mathrm{~h} / \mathrm{d}$ compared with $15-16 \mathrm{~h} / \mathrm{d}$ in patients with COPD. Although the group with LTOT $24 \mathrm{~h} / \mathrm{d}$ had statistically significantly lower baseline $\mathrm{PaO}_{2}$, potentially indicating more severe disease, the analyses adjusted for $\mathrm{PaO}_{2}$ and subsequently no independent difference in the associations with number of hospitalizations was found.

Although LTOT has been reported to decrease the risk for hospitalization ${ }^{1,2}$ and death, ${ }^{7}$ the optimal daily duration for LTOT is still unclear. The current recommendation to use LTOT $15 \mathrm{~h} / \mathrm{d}$ and preferably higher is based on pooled results from the MRC and NOTT studies where LTOT $15 \mathrm{~h} / \mathrm{d}$ and $24 \mathrm{~h} / \mathrm{d}$, respectively, were both associated with increased survival compared with no or with only nocturnal oxygen. ${ }^{1,2}$ However, our recently published work with the Swedish registry data indicates that there may indeed be no survival benefit from using LTOT continuously compared with LTOT 15-16 $\mathrm{h} / \mathrm{d} .{ }^{4}$ In the present study, time to first hospitalization was analyzed as primary outcome instead of time to death. Our results showing that the rate of hospitalizations was equal in patients with $24 \mathrm{~h} / \mathrm{d}$ and $15-16 \mathrm{~h} / \mathrm{d}$ is consistent with the previous finding of similar mortality risk in these groups. ${ }^{4}$ The present findings reflect real-world data and thus have high external validity, as patients starting LTOT today are older, have more comorbid conditions, and include more women compared with the MRC and NOTT studies. ${ }^{1,2}$

As for the other results of the Fine-Gray regression model, several cardiovascular diagnoses, maintenance treatment with oral glucocorticoids and lower $\mathrm{PaCO}_{2}$ were all associated with a higher risk for hospitalization. Cardiovascular comorbidity has been previously shown to influence risk for hospitalization in patients with COPD, ${ }^{20,21}$ and our association of oral steroids with an increased risk for hospitalization is consistent with a corresponding report of higher mortality risk in COPD and maintenance treatment with oral steroids. As for the unexpected association of higher $\mathrm{PaCO}_{2}$ with a lower risk for hospitalization, we speculate that a possible explanation may be due to some patients having coexisting overlap syndrome, where $\mathrm{PaCO}_{2}$ is higher but home ventilator therapy prevents hospitalizations. However, we do not have data on number of home ventilators in our study.

\section{Strengths and limitations}

The major strengths of this study is that it is a multicenter, national study with a large study population and that the Swedish register data used for patient characteristics and outcome variables are well reliable. ${ }^{13,14,16}$ A major limitation is that we have no objective data on actual daily oxygen utilization. Therefore, we cannot exclude the possibility that patients prescribed LTOT $24 \mathrm{~h} / \mathrm{d}$ utilized oxygen for fewer hours per day in real life or that patients prescribed 15-16 h/d used oxygen more. If this was the case, this could explain why no differences in hospitalization were found. However, our findings reflect effectiveness of prescribed oxygen durations in clinical practice, and a previous study has indicated that patients with significant hypoxemia as in our study population are adherent to prescribed LTOT duration. ${ }^{22}$ Another limitation is that the Swedevox data reports prescribed oxygen duration at baseline, and we cannot exclude that patients are either increasing or decreasing their prescribed dose of oxygen. In addition, there may be a selection bias due to doctor's decisions, where factors like comorbid pulmonary hypertension and functional status may influence the choice of oxygen duration. Finally, the observational design of the study means that the results may be biased, as the groups are not randomized. Although we tried to deal with this using a multivariate model with adjustment for potential confounders, our hypothesis that LTOT $24 \mathrm{~h} / \mathrm{d}$ does not lower the risk for mortality or hospitalizations compared with LTOT $15-16 \mathrm{~h} / \mathrm{d}$ needs to be examined in a randomized controlled trial.

\section{Clinical implications}

The results of this study support that there are no benefits of prescribing LTOT $24 \mathrm{~h} / \mathrm{d}$ compared with 15-16 h/d for prevention of hospitalizations. This finding, together with our previous study where no differences in survival was shown for LTOT 24 vs 15-16 h/d, could be of great clinical importance for the small but resource-intensive group of patients with hypoxemia due to COPD. LTOT is associated with considerable costs and side effects, and may lead to social isolation. ${ }^{12,23,24}$ In addition, low-flow oxygen therapy has been shown to be associated with oxidative stress and inflammation, which potentially could contribute to increased morbidity and negative health effects. ${ }^{25,26}$ Subsequently, it is important to establish that LTOT $24 \mathrm{~h} / \mathrm{d}$ is an unnecessary burden to patients with oxygen-dependent COPD.

\section{Conclusion}

LTOT prescribed $24 \mathrm{~h} / \mathrm{d}$ was not associated with decreased hospital admissions compared with LTOT $15-16 \mathrm{~h} / \mathrm{d}$ in patients with oxygen-dependent COPD. The results need to be further examined in a randomized controlled trial.

\section{Acknowledgment}

We thank Swedevox for supplying data for the study.

\section{Disclosure}

The authors report no conflicts of interest in this work. 


\section{References}

1. Nocturnal Oxygen Therapy Trial Group. Continuous or nocturnal oxygen therapy in hypoxemic chronic obstructive lung disease: a clinical trial. Ann Intern Med. 1980;93(3):391-398.

2. Medical Research Council Working Party. Long term domiciliary oxygen therapy in chronic hypoxic cor pulmonale complicating chronic bronchitis and emphysema. Report of the Medical Research Council Working Party. Lancet. 1981;1(8222):681-686.

3. Anthonisen NR. Prognosis in chronic obstructive pulmonary disease: results from multicenter clinical trials. Am Rev Respir Dis. 1989;140(3 Pt2): S95-S99.

4. Ahmadi Z, Sundh J, Bornefalk-Hermansson A, Ekström M. Longterm oxygen therapy 24 vs $15 \mathrm{~h} / \mathrm{d}$ and mortality in chronic obstructive pulmonary disease. PLoS One. 2016;11(9):e0163293.

5. Coquart JB, Le Rouzic O, Racil G, Wallaert B, Grosbois JM. Real-life feasibility and effectiveness of home-based pulmonary rehabilitation in chronic obstructive pulmonary disease requiring medical equipment. Int J Chron Obstruct Pulmon Dis. 2017;12:3549-3556.

6. Garcia-Aymerich J, Monsó E, Marrades RM, et al. Risk factors for hospitalization for a chronic obstructive pulmonary disease exacerbation. EFRAM study. Am J Respir Crit Care Med. 2001;164(6):1002-1007.

7. Ringbaek TJ, Viskum K, Lange P. Does long-term oxygen therapy reduce hospitalisation in hypoxaemic chronic obstructive pulmonary disease? Eur Respir J. 2002;20(1):38-42.

8. Albert RK, Au DH, Blackford AL, et al; Long-Term Oxygen Treatment Trial Research Group. A randomized trial of long-term oxygen for COPD with moderate desaturation. N Engl J Med. 2016;375(17): 1617-1627.

9. Turner AM, Sen S, Steeley C, et al. Evaluation of oxygen prescription in relation to hospital admission rate in patients with chronic obstructive pulmonary disease. BMC Pulm Med. 2014;14:127.

10. Ringbaek T, Martinez G, Lange P. The long-term effect of ambulatory oxygen in normoxaemic COPD patients: a randomised study. Chron Respir Dis. 2013;10(2):77-84.

11. Ring L, Danielson E. Patients' experiences of long-term oxygen therapy. J Adv Nurs. 1997;26(2):337-344.

12. Disler RT, Green A, Luckett T, et al. Experience of advanced chronic obstructive pulmonary disease: metasynthesis of qualitative research. J Pain Symptom Manage. 2014;48(6):1182-1199.

13. Ekström M, Ahmadi Z, Larsson H, et al. A nationwide structure for valid long-term oxygen therapy: 29-year prospective data in Sweden. Int J Chron Obstruct Pulmon Dis. 2017;12:3159-3169.
14. Ludvigsson JF, Andersson E, Ekbom A, et al. External review and validation of the Swedish national inpatient register. BMC Public Health. 2011;11:450.

15. Wettermark B, Hammar N, Fored CM, et al. The new Swedish Prescribed Drug Register - opportunities for pharmacoepidemiological research and experience from the first 6 months. Pharmacoepidemiol Drug Saf. 2007;16(7):726-735.

16. Brooke HL, Talbäck M, Hörnblad J, et al. The Swedish cause of death register. Eur J Epidemiol. 2017;32(9):765-773.

17. Ekström MP, Hermansson AB, Ström KE. Effects of cardiovascular drugs on mortality in severe chronic obstructive pulmonary disease. Am J Respir Crit Care Med. 2013;187(7):715-720.

18. Ekström MP, Bornefalk-Hermansson A, Abernethy AP, Currow DC. Safety of benzodiazepines and opioids in very severe respiratory disease: national prospective study. BMJ. 2014;348:g445.

19. Ahmadi Z, Bornefalk-Hermansson A, Franklin KA, Midgren B, Ekström MP. Hypo- and hypercapnia predict mortality in oxygendependent chronic obstructive pulmonary disease: a population-based prospective study. Respir Res. 2014;15:30.

20. Curkendall SM, DeLuise C, Jones JK, et al. Cardiovascular disease in patients with chronic obstructive pulmonary disease, Saskatchewan Canada cardiovascular disease in COPD patients. Ann Epidemiol. 2006;16(1):63-70.

21. Mannino DM, Thorn D, Swensen A, Holguin F. Prevalence and outcomes of diabetes, hypertension and cardiovascular disease in COPD. Eur Respir J. 2008;32(4):962-969.

22. Katsenos S, Constantopoulos SH. Long-term oxygen therapy in COPD: factors affecting and ways of improving patient compliance. Pulm Med. 2011;2011:325362.

23. Croxton TL, Bailey WC. Long-term oxygen treatment in chronic obstructive pulmonary disease: recommendations for future research: an NHLBI workshop report. Am J Respir Crit Care Med. 2006;174(4): 373-378.

24. Stoller JK, Panos RJ, Krachman S, Doherty DE, Make B; Long-term Oxygen Treatment Trial Research Group. Oxygen therapy for patients with COPD: current evidence and the long-term oxygen treatment trial. Chest. 2010;138(1):179-187.

25. Foschino Barbaro MP, Serviddio G, Resta O, et al. Oxygen therapy at low flow causes oxidative stress in chronic obstructive pulmonary disease: prevention by N-acetyl cysteine. Free Radic Res. 2005;39(10): 1111-1118.

26. Holguin F, Folch E, Redd SC, Mannino DM. Comorbidity and mortality in COPD-related hospitalizations in the United States, 1979-2001. Chest. 2005;128(4):2005-2011.
International Journal of COPD

\section{Publish your work in this journal}

The International Journal of COPD is an international, peer-reviewed journal of therapeutics and pharmacology focusing on concise rapid reporting of clinical studies and reviews in COPD. Special focus is given to the pathophysiological processes underlying the disease, intervention programs, patient focused education, and self management protocols.

\section{Dovepress}

This journal is indexed on PubMed Central, MedLine and CAS. The manuscript management system is completely online and includes a very quick and fair peer-review system, which is all easy to use. Visit http://www.dovepress.com/testimonials.php to read real quotes from published authors. 